\title{
Pelatihan Petugas Keamanan tentang Penanganan Pertama Kegawatdaruratan (Basic Life Support) di Universitas Muslim Indonesia
}

\author{
Arni Isnaini Arfah, ${ }^{1 *}$ Arina F. Arifin, ${ }^{2}$ Ilma Khaerina A.B ${ }^{3}$ \\ ${ }^{1}$ Departemen Fisiologi, Fakultas Kedokteran, Universitas Muslim Indonesia \\ ${ }^{2}$ Departemen Histologi, Fakultas Kedokteran, Universitas Muslim Indonesia \\ ${ }^{3}$ Departemen Farmakologi, Fakultas Kedokteran, Universitas Muslim Indonesia
}

*Email korespondensi: arniisnaini.arfah@umi.ac.id

Telp: 085255491100

\begin{abstract}
ABSTRAK
Basic Life Support atau istilah awamnya Bantuan Hidup Dasar (BHD) adalah tindakan darurat untuk membebaskan jalan napas, membantu pernapasan dan mempertahankan sirkulasi darah tanpa menggunakan alat bantu. Salah satu poros utama sebagai garda terdepan yang paling sering menemui kejadian gawat darurat adalah satuan pengamanan (satpam) kampus. Sering kali, karena pertolongan yang tidak sesuai prosedur malah meningkatkan keparahan kondisi kegawatdaruratan. Oleh karena itu perlu adanya pelatihan dan penerapan bantuan hidup dasar utamanya pada satpam kampus agar mampu menolong korban minimal mampu menstabilkan kondisi korban saat pertolongan pertama. Metode yang digunakan pada pelatihan ini merupakan pelatihan partisipatif, yakni di harapkan seluruh peserta ikut aktif dan mampu melakukan keterampilan dari pelatihan. Adapun luaran yang dihasilkan dari kegiatan pengabdian ini, peserta diberikan materi-materi penanganan pertama kegawatdaruratan serta mempraktekkan skill tersebut oleh masing-masing peserta, serta disebarluaskan pelatihan ini di media cetak. Program yang disepakati dan akan dilaksanakan dengan mitra meliputi: Teknik pertolongan pertama pada kecelakaan ataupun kegawatdaruratan lainnya dalam pembebasan jalan nafas ataupun pijatan jantung luar, teknik penanganan management syok, teknik serta pengangkutan dan mobilisasi korban, teknik stabilisasi kepala dan leher, teknik melakukan evakuasi yang benar dan aman.
\end{abstract}

Kata kunci: Basic Life Support; pertolongan pertama; tindakan darurat

\begin{abstract}
Basic Life Support or layman's terms Bantuan Hidup Dasar (BHD) is an emergency measure to free the airway, help breathing and maintain blood circulation without using tools. One of the main axes as the front guard that most often encounters emergency events is the campus security guard. Often, because help that does not fit the procedure actually increases the severity of the emergency condition. Therefore there is a need for training and implementation of basic life support, especially on campus security to be able to help victims at least be able to stabilize the condition of victims during first aid. The method used in this training is participatory training, which is expected that all participants will actively participate and be able to perform the skills of the training. As for the outcomes resulting from these community service activities, participants were given the first emergency handling materials and practiced these skills by each participant, and the training was disseminated in print media. Programs agreed upon and will be implemented with partners include: First aid techniques in accidents or other emergencies in freeing airway or external cardiac massage, shock management handling techniques, techniques and transporting and mobilizing victims, stabilization techniques of the head and neck, techniques for correct evacuation and safe.
\end{abstract}

Keywords: Basic Life Support; first aid; emergency service 


\section{PENDAHULUAN}

Basic Life Support atau istilah awamnya Bantuan Hidup Dasar (BHD) adalah tindakan darurat untuk membebaskan jalan napas, membantu perrnapasan dan mempertahankan sirkulasi darah tanpa menggunakan alat bantu. $(1,2)$

Kasus-kasus penyebab terjadinya henti jantung dan henti napas dapat terjadi kapan saja, dimana saja, dan pada siapa saja. Pengelolaan rencana menghadapi kegawatdaruratan ini harus menggunakan serangkaian kesepakatan yang telah disetujui untuk mengatasi semua jenis bahaya. Daripada mengembangkan rencana dan prosedur yang berbeda untuk setiap kegawatdaruratan, maka penanganan tersebut seharusnya dikembangkan dan diterapkan untuk semua kegawatdaruratan yang dihadapi oleh masyarakat, namun harus terarah dan terpadu sehingga masyarakat sendiri mampu mencegah cedera korban menjadi lebih parah saat penanganan awal kegawatdaruratan. $(3,4)$

RJP dibagi dalam 3 tahap, yaitu Bantuan Hidup Dasar (BHD), bantuan hidup lanjut, bantuan hidup jangka panjang. Bantuan hidup dasar merupakan usaha untuk melakukan oksigenasi darurat dan terdiri dari langkah-langkah; airway control = penguasaan jalan napas; Breathing support = bantuan pernapasan dengan ventilasi buatan dan oksigenasi pada paru; Circulation support $=$ bantuan sirkulasi dengan mengevaluasi denyut nadi dan melakukan sirkulasi buatan dengan kompresi jantung dan mengatasi perdarahan. $(5,6)$

Berdasarkan AHA (2015), setelah menilai tingkat kesadaran korban, evaluasi jalan napas korban. Ingat, jika korban waspada dan berbicara, berarti jalan napas terbuka. Begitu korban tidak responsif, cari bantuan dan menilai jalan napas korban. Hal ini memerlukan posisi telentang pada permukaan datar dan keras dengan lengan di sepanjang sisi tubuh, diikuti dengan membuka saluran napas korban tersebut. Kecuali trauma dapat dieksklusi, setiap gerakan korban harus memperhitungkan potensi cedera tulang belakang. Korban ditempatkan telentang, menstabilkan tulang belakang leher dengan mempertahankan kepala, leher, dan badan dalam garis lurus. $(5,7)$

Bantuan pernapasan dapat dilakukan dengan metode: Teknik Ventilasi Mouth to Mouth, Mulut ke Hidung, Mulut ke Stoma atau Trakeostomi, dan Mulut ke Sungkup Muka. Manuver yang digunakan untuk menghilangkan sumbatan jalan napas akibat benda asing meliputi manuver Heimlich (penekanan pada sub diafragma perut), Back blow, chest thrust, dan finger sweep. $(8,9)$

Jika tidak ada denyut nadi setelah 5 sampai 10 detik, kompresi dada harus dimulai. Penolong tidak terlatih harus memberikan RJP hanya kompresi (Hands-Only) dengan atau tanpa panduan operator untuk korban serangan jantung dewasa. Penolong harus melanjutkan 
RJP hanya kompresi hingga AED atau penolong dengan pelatihan tambahan tiba. Selain itu, jika penolong terlatih mampu melakukan napas buatan, ia harus menambahkan napas buatan dalam rasio 30 kompresi berbanding 2 napas buatan. $(5,10)$

Salah satu poros utama sebagai garda terdepan yang paling sering menemui kejadian gawat darurat adalah satuan pengamanan (satpam) kampus. Sering kali, karena pertolongan yang tidak sesuai prosedur malah meningkatkan keparahan kondisi kegawatdaruratan. Oleh karena itu perlu adanya pelatihan dan penerapan bantuan hidup dasar utamanya pada satpam kampus agar mampu menolong korban minimal mampu menstabilkan kondisi korban saat pertolongan pertama.

\section{METODE PELAKSANAAN}

\subsection{Solusi dan Target Luaran :}

Pelatihan ini dapat dijadikan bekal mitra dalam memberikan pertolongan pertama pada kondisi-kondisi gawat darurat yang terjadi di sekitar mereka dengan materi dan simulasi yang sudah dilakukan. Adapun target yang telah diapat dari nilai pretest rerata jawaban peserta $49 \%$ dan setelah pelatihan nilai posttest rerata jawaban peserta $63 \%$.

\subsection{Lokasi Kegiatan Pelaksanaan}

Waktu Pelaksanaan bulan November 2019 di Fakultas Kedokteran Universitas Muslim Indonesia.

\subsection{Metode Kegiatan}

Metode yang digunakan pada pelatihan ini merupakan pelatihan partisipatif, yakni seluruh peserta ikut aktif dan mampu melakukan keterampilan dari pelatihan. Program yang disepakati dan akan dilaksanakan dengan mitra meliputi: Teknik pertolongan pertama pada kecelakaan ataupun kegawatdaruratan lainnya dalam pembebasan jalan nafas ataupun pijatan jantung luar, teknik penanganan management syok, teknik serta pengangkutan dan mobilisasi korban, teknik stabilisasi kepala dan leher, teknik melakukan evakuasi yang benar dan aman, serta penaganan pasien trauma.

Kegiatan dilaksanakan dalam bentuk pelatihan. Peserta akan diberikan materi dan akan dipraktekkan langsung oleh tim instruktur. Kemudian peserta akan dibagi menjadi kelompok kecil yang didampingi oleh instruktur, sehingga peserta dapat mempraktekkan sendiri. 


\section{HASIL DAN PEMBAHASAN}

Selama kegiatan berlangsung peserta cukup aktif, sebab dari hasil pre test yang diberikan ada peningkatan pengetahuan peserta terhadap pelatihan yang telah diberikan, namun masih perlu adanya feedback terhadap peningkatan keterampilan terhadap pelatihan tersebut. Kegiatan seperti ini baik jika peserta atau masyarakat awam lebih sering terpapar, sebab ada sebagian peserta masih perlu lebih ditingkatkan keterampilannya.

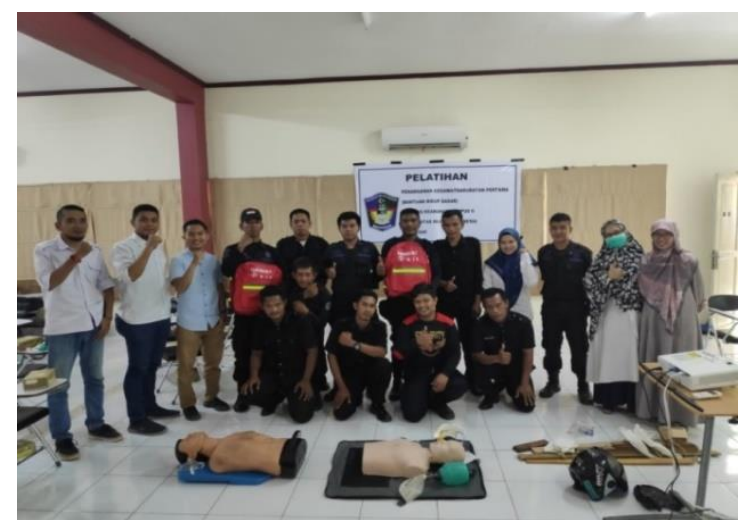

Gambar 1. Foto Pelatihan Basic Life Support

Sebelum dilaksanakan pelatihan, peserta akan diberikan test untuk mengetahui sejauh mana peserta pelatihan ini mengetahui tentang kegawatdaruratan dan penanganannya sehari-hari bagi masyarakat awam, kemudian seharian full peserta akan diberikan pelatihan dan diakhir pelatihan mereka akan diberikan test lagi untuk menilai ada tidaknya peningkatan pengetahuan dan keterampilan peserta tentang kegawatdaruratan bagi masyarakat awam.

Adapun hasil dari pretest dan postest tersebut yaitu:

\begin{tabular}{|c|c|c|c|c|c|c|c|c|c|c|c|c|c|c|c|c|}
\hline & 1 & 2 & 3 & 4 & 5 & 6 & 7 & 8 & 9 & 10 & 11 & 12 & 13 & 14 & 15 & 16 \\
\hline Pretest & $4 / 10$ & $5 / 10$ & $5 / 10$ & $6 / 10$ & $7 / 10$ & $5 / 10$ & $6 / 10$ & $6 / 10$ & $4 / 10$ & $4 / 10$ & $5 / 10$ & $5 / 10$ & $4 / 10$ & $2 / 10$ & $4 / 10$ & $7 / 10$ \\
\hline Postest & $7 / 10$ & $5 / 10$ & $7 / 10$ & $8 / 10$ & $9 / 10$ & $7 / 10$ & $6 / 10$ & $5 / 10$ & $7 / 10$ & $5 / 10$ & $6 / 10$ & $6 / 10$ & $5 / 10$ & $5 / 10$ & $5 / 10$ & $8 / 10$ \\
\hline
\end{tabular}

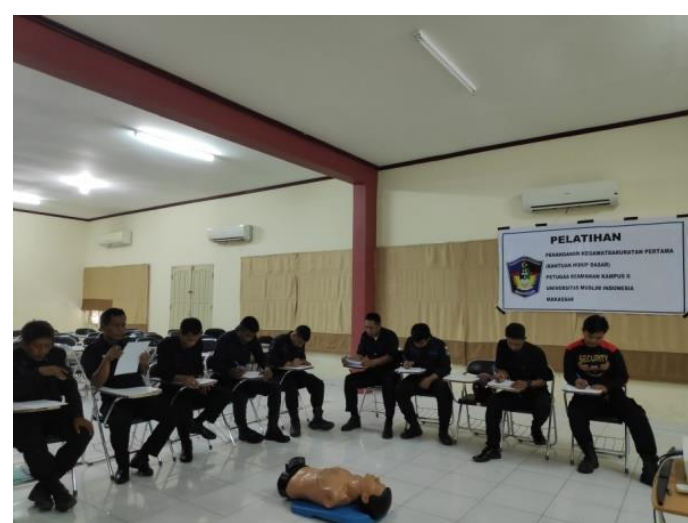

Gambar 2. Pretest

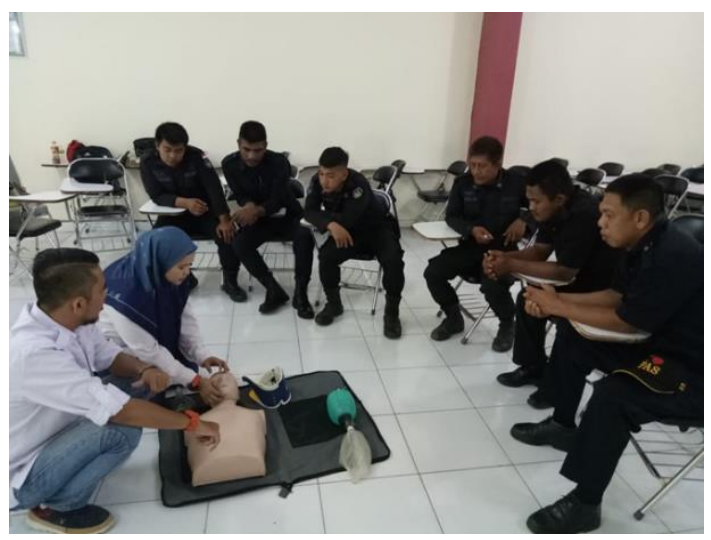

Gambar 3. Simulasi Skill 


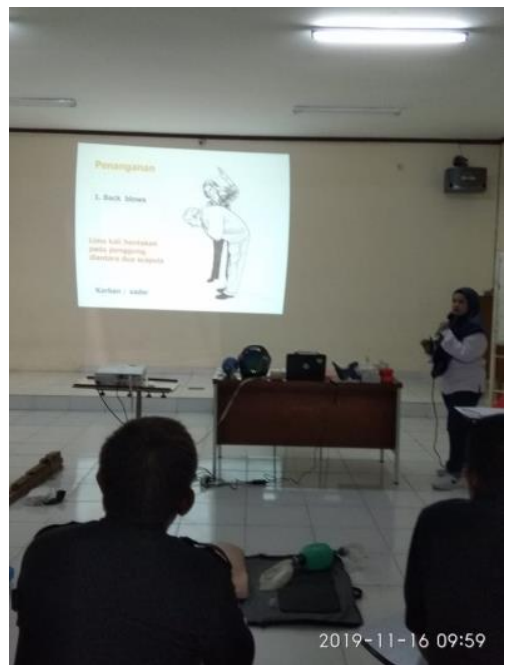

Gambar 4. Materi

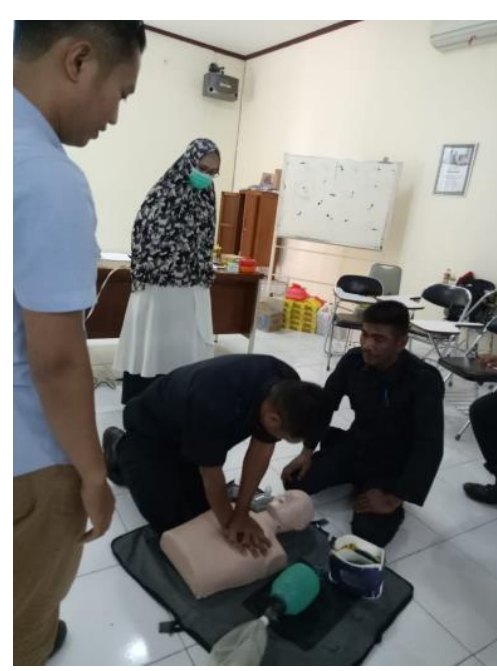

Gambar 5. Simulasi Skill

\section{KESIMPULAN DAN SARAN}

Peserta mampu mengetahui pengertian Basic Life Support (Bantuan Hidup Dasar) setelah pelatihan. Peserta mampu melakukan penanganan kegawatdaruratan pertama (Basic Life Support) setelah pelatihan. Pelatihan ini sebaiknya dibuat sesering mungkin, agar supaya peserta semakin baik dalam tindakan kegawatdaruratan. Sebaiknya dibuatkan kegiatan simulasi kegawatdaruratan bagi masyarakat awam khususnya petugas keamanan kampus II UMI.

\section{Ucapan Terima Kasih}

Dekan dan pimpinan fakultas kedokteran serta lembaga LP3M UMI dan UP3M Fakultas Kedokteran UMI. 


\section{DAFTAR PUSTAKA}

1. Roshana S. Basic life support: knowledge and attitude of medical/paramedical professionals. World J Emerg Med. 2012;3(2):141.

2. Venn R. Basic life support. Crit Care. 2000;2(1):194-9.

3. Collins SP, Storrow AB, Levy PD, Albert N, Butler J, Ezekowitz JA, et al. Early management of patients with acute heart failure: State of the art and future directions - A consensus document from the SAEM/HFSA acute heart failure working group. Acad Emerg Med. 2015;22(1):94-112.

4. Butz AM. Cardiac Arrest: Resuscitation and Reperfusion Kaustubha. Physiol Behav. 2017;176(12):139-48.

5. Walter Alexander. American Heart Association Meetings. Crit Pathways Cardiol A J Evidence-Based Med. 2005;4(1):51-3.

6. Cave DM, Gazmuri RJ, Otto CW, Nadkarni VM, Cheng A, Brooks SC, et al. CPR Techniques and Devices: 2013;122.

7. Chipman C, Adelman R, Sexton G. Criteria for cessation of CPR in the emergency department. Ann Emerg Med. 1981;10(1):11-7.

8. Quintana ARG, Atallah ÁN, Saconato H, Wale JL, Melnik T. Respiratory therapy for removing bronchial secretions in mechanically ventilated adult patients. Cochrane Database Syst Rev. 2013;2013(2):2-5.

9. InformedHealth.org. Giving mouth-to-mouth resuscitation. In Cologne, lGermany: Institute for Quality and Efficiency in Health Care; 2017.

10. Vafaei A, Shams Akhtari A, Heidari K, Hosseini S. Quality of Cardiopulmonary Resuscitation in Emergency Department Based on the AHA 2015 Guidelines; a Brief Report. Emerg (Tehran, Iran). 2018;6(1):e46. 